\title{
Efficient Extraction of Starch from Microalgae Using Ultrasonic Homogenizer and Its Conversion into Ethanol by Simultaneous Saccharification and Fermentation
}

\author{
Chikako Asada, Keita Doi, Chizuru Sasaki, Yoshitoshi Nakamura* \\ Department of Life System, Institute of Technology and Science, University of Tokushima, Tokushima, Japan. \\ Email: ${ }^{*}$ ynakamu@bio.tokushima-u.ac.jp
}

Received October $16^{\text {th }}, 2012$; revised November $18^{\text {th }}, 2012$; accepted November $29^{\text {th }}, 2012$

\begin{abstract}
To utilize starch and protein contained in microalgae as carbon and nitrogen sources for ethanol production, an extraction method, i.e. ultrasonic treatment using a homogenizer, and simultaneous saccharification and fermentation (SSF) of extracted microalgae solution were studied using Chlamydomonas fasciata Ettl $437.30 \mathrm{~min}$ of ultrasonic treatment gave the maximum extraction ratio of starch contained in microalgae, i.e. $93.8 \%$, that corresponded to $0.408 \mathrm{~g}$-starch/g-dry microalgae. SSF of the extracted solution obtained from ultrasonic treated microalgae at $30 \mathrm{~min}$ by glutase-AN and Saccahromyces cerevisiae AM12 provided 0.194 and 0.168 g-ethanol/g-dry microalgae with and without yeast extract, respectively, corresponding to 79.5 and $68.8 \%$ of theoretical ethanol yield.
\end{abstract}

Keywords: Bioethanol; Microalgae; Ultrasonic Treatment; Homoginizer; Starch

\section{Introduction}

In late years bioethanol has been considered as a candidate of alternative energy of fossil resources [1,2]. Production of bioethanol from corn and sugar cane as raw materials is performed in industrial level, but the remarkable rise of cereals occurs globally because they are also used as food. Recently, many researchers have studies on ethanol production from lignocellulosic material, i.e. wood, bagasse, straw, and etc., which does not compete with food. However, since lignocellulosic materials undergoes lignifications and the pretreatment method, i.e. delignification method, is necessary for the effective saccharification and fermentation of lignocellulosic materials [3-5], it is desired for cost-effective bioethanol production to use other biomass as a source of bioethanol production. On the other hand, microalgae have been attracted as the most promisingly renewable resource for bioethanol production because of their faster growth rate, higher photosynthetic efficiency and polysaccharide production compared with other energy biomass [6-9]. A major obstacle of bioethanol production from microalgae is its hard cell wall that covered starch, a substrate of bioethanol production, contained in microalgae strongly. Therefore, it is necessary to degrade and/or remove the cell wall and enhance accessibility of starch to enzyme

"Corresponding author. and microorganism.

Recently, ultrasonic technologies have been used as pretreatment methods in various industrial fields for decades. For examples, ultrasonic treatments were used to hydrolyze starch contained in corn for increasing enzymatic susceptibility but also to improve melt processing of starch contained in corn [10-12]. Furthermore, Lomboy et al. [13] reported that the total cost of ultrasonic treatment was lower than that of conventional jet cookers for corn dry-grind ethanol plants.

In this work, the efficient extraction of starch from microalgae using ultrasonic homogenizer and its conversion into ethanol by simultaneous saccharification and fermentation (SSF) were attempted. The effect of ultrasonic treatment on extraction of starch was clarified and the optimal condition of SSF was determined for the effective conversion of ultrasonic treated microalgae into ethanol.

\section{Materials and Methods}

\subsection{Microalgae Culture}

Chlamydomonas fasciata Ettl NIES-437 provided by MICROBIAL CULTURE COLLECTION at National Institute for Environmental Studies, Japan was used as a microalga in this study. The culture experiment was carried out at $25^{\circ} \mathrm{C}$ and $\mathrm{pH} 7.5$ in a $10 \mathrm{~L}$ stirred photobiore- 
actor containing $6 \mathrm{~L}$ of medium. The carbon source, i.e. $\mathrm{CO}_{2}$, was supplied by bubbling air at an aeration rate of 4 vvm. A light level of 3000 lux was provided by fluorescent lamps continuously. The medium used in this work had the following composition: $150 \mathrm{mg} / \mathrm{L} \mathrm{Ca}\left(\mathrm{NO}_{3}\right) \cdot 4 \mathrm{H}_{2} \mathrm{O}$, $100 \mathrm{mg} / \mathrm{L} \mathrm{KNO}_{3}, 50 \mathrm{mg} / \mathrm{L} \beta$-glycero-phosphoric acid, 40 $\mathrm{mg} / \mathrm{L} \mathrm{MgSO}{ }_{4} \cdot 7 \mathrm{H}_{2} \mathrm{O}, 0.0001 \mathrm{mg} / \mathrm{L}$ vitamine B12, 0.0001 $\mathrm{mg} / \mathrm{L}$ biotin, $0.01 \mathrm{mg} / \mathrm{L}$ thiamin hydrochloride, 0.558 $\mathrm{mg} / \mathrm{L} \quad \mathrm{FeCl}_{3} \cdot 6 \mathrm{H}_{2} \mathrm{O}, 0.108 \mathrm{mg} / \mathrm{L} \quad \mathrm{MnCl}_{2} \cdot 4 \mathrm{H}_{2} \mathrm{O}, 0.066$ $\mathrm{mg} / \mathrm{L} \mathrm{ZnSO} \mathrm{Zn}_{4} \cdot 7 \mathrm{H}_{2} \mathrm{O}, 0.012 \mathrm{mg} / \mathrm{L} \quad \mathrm{CoCl}_{2} \cdot 6 \mathrm{H}_{2} \mathrm{O}, 0.0075$ $\mathrm{mg} / \mathrm{L} \mathrm{Na} \mathrm{MoO}_{4} \cdot 2 \mathrm{H}_{2} \mathrm{O}, 3 \mathrm{mg} / \mathrm{L} \mathrm{Na} \mathrm{EDTA}_{2} \cdot 2 \mathrm{H}_{2} \mathrm{O}$, and 500 $\mathrm{mg} / \mathrm{L}$ tris (hydoxymethyl) aminomethane in distilled water. Microalgae and culture were withdrawn from the photobioreactor for measuring the growth amount of microalgae. Microalgae were collected by a centrifugation at $12,000 \mathrm{~g}$ during $20 \mathrm{~min}$ and then washed with distilled water and methanol for measuring dry cell weight and chlorophyll content in the microalgae, respectively. The chlorophyll content was measured according to the method reported by Grimme and Boardman [14].

\subsection{Extraction and Measurement Method of Starch from Microalgae}

For efficient extraction of starch from microalgae, dry 2 $\mathrm{g}$ of microalgae was added into $20 \mathrm{~mL}$ distilled water and then mixed using a vortex followed by ultrasonic treated using a homogenizer (Branson Sonifier 250, Emerson Japan Ltd.) with $30 \mathrm{~W}$ and $20 \mathrm{kHz}$ for $0-40 \mathrm{~min}$. The sample was taken from the extracted solution obtained from ultrasonic treated microalgae and used for composition analysis. Starch, protein, and ash content were determined using AOAC method [15]. Glucose content was measured by the mutarotase GOD method (Glucose C-Test; Wako Pure Chemical, Osaka, Japan). All analytical determinations were performed in triplicate and average results are shown.

\subsection{Alcohol Fermenting Yeast and Inoculum Cultivation}

A heat-tolerant alcohol fermenting yeast, Saccharomyces cerevisiae AM12, provided by Bioacademia Co. Ltd., Japan, was used for the SSF experiments. The microorganism was precultured in $100 \mathrm{~mL}$ of medium in a 300 -mL flask at $40^{\circ} \mathrm{C}$ for $24 \mathrm{~h}$ using an orbital shaker at $60 \mathrm{rpm}$. The media for preculture were as follows: 0.1 $\mathrm{g} / \mathrm{L}\left(\mathrm{NH}_{4}\right)_{2} \mathrm{SO}_{4}, 10 \mathrm{~g} / \mathrm{L}$ glucose, $0.1 \mathrm{~g} / \mathrm{L} \mathrm{KH}_{2} \mathrm{PO}_{4}, 0.1 \mathrm{~g} / \mathrm{L}$ $\mathrm{MgSO}_{4} \cdot 7 \mathrm{H}_{2} \mathrm{O}$, and $1.0 \mathrm{~g} / \mathrm{L}$ yeast extract. Thereafter, the cells were collected by centrifugation at $2000 \mathrm{~g}$ during 15 min, rinsed thoroughly with sterile distilled water, centrifuged again, and then resuspended in sterile distilled water.

\subsection{Simultaneous Saccharification and Fermentation (SSF) Conditions}

The medium for SSF contained the extracted solution obtained from ultrasonic treated microalgae (with a substrate concentration of $10 \% \mathrm{w} / \mathrm{v}$ ), nutrient medium, 0.05 $\mathrm{M}$ acetate buffer ( $\mathrm{pH} 5.0)$, glutase-AN $(0.1 \% \mathrm{w} / \mathrm{v})$, and $10 \% \mathrm{v} / \mathrm{v}$ preculture solution. Glutase-AN (produced by Aspergillus niger, $13,000 \mathrm{u} / \mathrm{g}$, where $\mathrm{u}$ is the amount of enzyme that hydrolyses soluble starch to produce $10 \mathrm{mg}$ of glucose every $30 \mathrm{~min}$ at $40^{\circ} \mathrm{C}$ and $\mathrm{pH} 5.0$ ) was provided by HBI Enzymes Inc. The extracted solution, nutrient medium, and buffer were autoclaved at $121^{\circ} \mathrm{C}$ for $20 \mathrm{~min}$, but the enzyme solution was added after sterilization using a $0.22-\mu \mathrm{m}$-pore size filter. The nutrient medium comprised $1.0 \mathrm{~g} / \mathrm{L}\left(\mathrm{NH}_{4}\right)_{2} \mathrm{HPO}_{4}, 0.05 \mathrm{~g} / \mathrm{L}$

$\mathrm{MgSO}_{4} \cdot 7 \mathrm{H}_{2} \mathrm{O}$, and $2.0 \mathrm{~g} / \mathrm{L}$ yeast extract [16]. Furthermore, the sterile distilled water containing cells described above was added to the medium and the initial concentration of cells was adjusted to $0.1 \% \mathrm{w} / \mathrm{v}$. SSF was performed in a $300-\mathrm{mL}$ flask with $100 \mathrm{~mL}$ of the medium using the orbital shaker at $100 \mathrm{rpm}$ for $30 \mathrm{~h}$ at $40^{\circ} \mathrm{C}$. Aliquots of the samples were then collected and assayed for ethanol and residual glucose concentrations.

\subsection{Analytical Methods}

Glucose and ethanol concentrations were determined by HPLC using a refractive index (RI) detector and a BioRad HPX-87H column at $65^{\circ} \mathrm{C} ; 5 \mathrm{mM} \mathrm{H}_{2} \mathrm{SO}_{4}$ was used as an eluent at a flow rate of $0.6 \mathrm{~mL} / \mathrm{min}$, and the injected sample volume was $10 \mu \mathrm{L}$. All fermentation experiments were performed in triplicate and average results are shown.

\section{Results and Discussion}

\subsection{Incubation of Microalgae}

Figure 1 shows the time courses of dry cell and chlorophyll concentration in the incubation of microalgae using

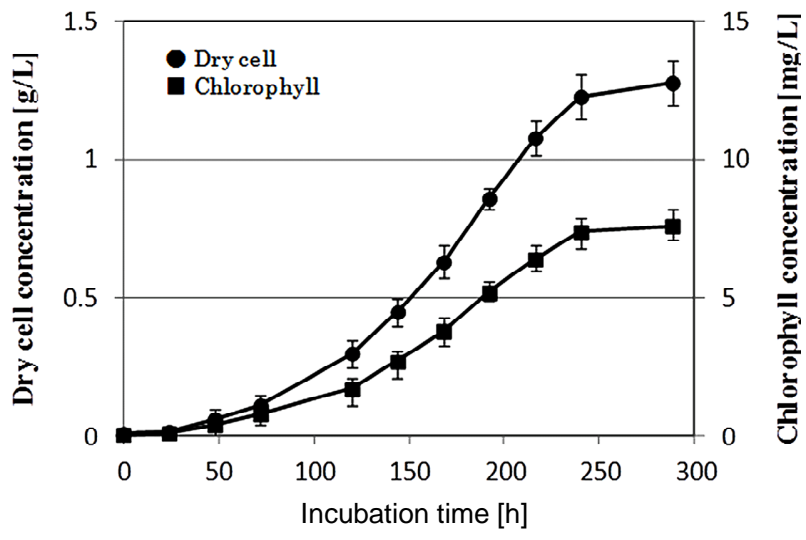

Figure 1. Growth profile of microalgae in photoreactor. 
the photo-bioreactor. In this experiment the initial concentration of dry cell and chlorophyll was about $0.17 \mathrm{~g} / \mathrm{L}$ and $0.1 \mathrm{mg} / \mathrm{L}$. The dry cell and chlorophyll concentration increased with the increase of incubation time reaching their maximum values, i.e. about $1.28 \mathrm{~g} / \mathrm{L}$ and $7.65 \mathrm{mg} / \mathrm{L}$, respectively, at an incubation time of $250 \mathrm{~h}$. As a result, it was found that $C$. fasciata Ettl 437 contains about $6 \mathrm{mg}$ of chlorophyll per unit of one gram of microalgae. Furthermore, from the result of composition analysis using dry microalgae, it was found that these microalgae contained $43.5 \%$ starch, $30.4 \%$ protein, $6.8 \%$ ash, and $19.3 \%$ others in the dry state.

\subsection{Extraction of Starch from Microalgae}

To increase the extraction ratio of starch from microalgae for effective conversion of starch into ethanol, the ultrasonic treatment was attempted using a homogenizer. Figure 2 shows the percentage ratios of amounts of starch and glucose extracted from $2 \mathrm{~g}$ of dry microalgae in $20 \mathrm{~mL}$ of water by the ultrasonic treatment at various treatment times. At zero treatment time no extraction of starch was observed, but $0.5 \mathrm{~min}$ of ultrasonic treatment could extract starch from microalgae. Though $0.5-5 \mathrm{~min}$ of ultrasonic treatment did not affect starch extraction ratio, i.e. about $18 \%$, beyond $5 \mathrm{~min}$ of ultrasonic treatment the starch extraction ratio increased significantly with the increase of treatment time and then reached a maximum value, i.e. $40.8 \%$, at $30 \mathrm{~min}$. Since as described above the dry microalgae contains $43.5 \%$ starch, $30 \mathrm{~min}$ of ultrasonic treatment seems to be enough for starch extraction from microalgae and the extraction ratio of starch contained in microalgae is calculated as $93.8 \%$. Solution temperature was increased rapidly from $24^{\circ} \mathrm{C}$ to $68^{\circ} \mathrm{C}$ by this treatment and it could also definitely affect the starch extraction efficiency. This point is a future subject. Furthermore, regardless of treatment time the glucose extraction ratio was maintained at a low constant

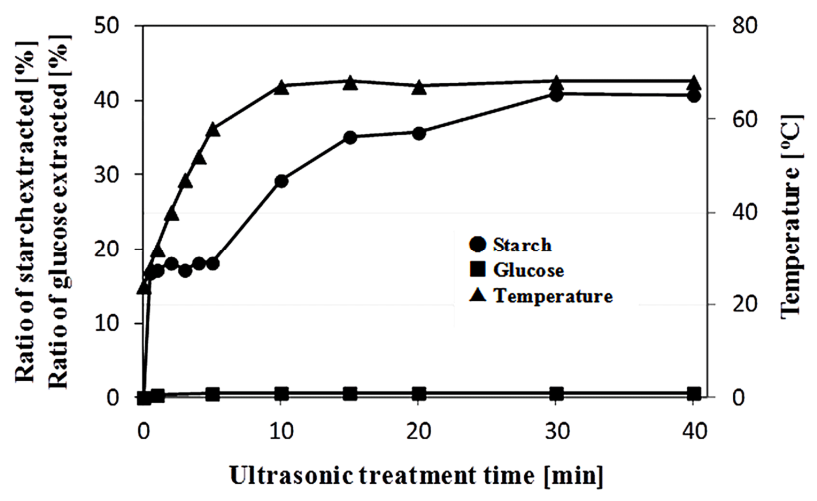

Figure 2. Ratios of amounts of starch and glucose extracted to dry weight of microalgae and change of solution temperature by ultrasonic homogenizer treatment. value, i.e. below $1 \%$. This means that the ultrasonic treatment does not degrade starch to glucose directly because it cannot break down $\alpha$-1,4- and/or $\beta$-1,6-glucoside linkages. On the other hand, in the case that the microalgae was crushed finely for 30 min with a mortar (data not shown), a lower starch extraction ratio, i.e. 14\%, was obtained and no further increase of extraction ratio was observed even at a longer crushing time. As a result, it was found that the ultrasonic treatment using a homogenizer is effective for not the degradation but the extraction of starch from microalgae. Since in this experiment the mixing ratio of microalgae (dry base) to water was $1 / 10$, a future study will be focused on evaluating the optimal mixing ratio of microalgae to water.

\subsection{Simultaneous Saccharification of Fermentation (SSF) of Extracted Solution Obtained from Ultrasonic Treated Microalgae}

Figure 3 shows SSF of microalgae crushed by a mortar and extracted solution obtained from ultrasonic treated microalgae. The initial dry microalgae concentration was $100 \mathrm{~g} / \mathrm{L}$. Before SSF of these extracted solutions, SSF of microalgae without neither crushing nor ultrasonic treatments was carried, but little amount of ethanol was produced (data not shown). This means that the direct conversion of microalgae into ethanol using only enzyme and yeast is difficult due to its resistant cell wall structure. In SSF of microalgae crushed by a mortar as shown in Figure 3(a), the glucose was produced from starch by the enzyme and then converted into ethanol by S. cerevisiae AM12, and only $6.94 \mathrm{~g} / \mathrm{L}$ of ethanol was obtained after $24 \mathrm{~h}$ of incubation time. Furthermore, in case of extracted solution obtained from ultrasonic treated microalgae for $5 \mathrm{~min}$ as shown in Figure 3(b), little effect for increasing ethanol production was observed. This means that a short ultrasonic treatment is not effective for the extraction of starch as shown in Figure 2. On the other hand, in case of extracted solution obtained from ultrasonic treated microalgae for $30 \mathrm{~min}$ as shown in Figure 3(c), a large amount of glucose was produced and then converted into ethanol, and $19.4 \mathrm{~g} / \mathrm{L}$ of ethanol was obtained after $24 \mathrm{~h}$ of incubation time. This ethanol yield, $0.194 \mathrm{~g} / \mathrm{g}$-dry microalgae, corresponds to $79.5 \%$ of the theoretical yield based on the total glucose from starch in microalgae.

Next, to study an economical ethanol production from microalgae and possibility of use of microalgae as not only carbon but also nitrogen sources, SSF was performed without supplying any additional nitrogen source, i.e. yeast extract. Figure 4 shows SSF of extracted solution obtained from ultrasonic treated microalgae at 30 min with no addition of nitrogen source. Though 16.8 


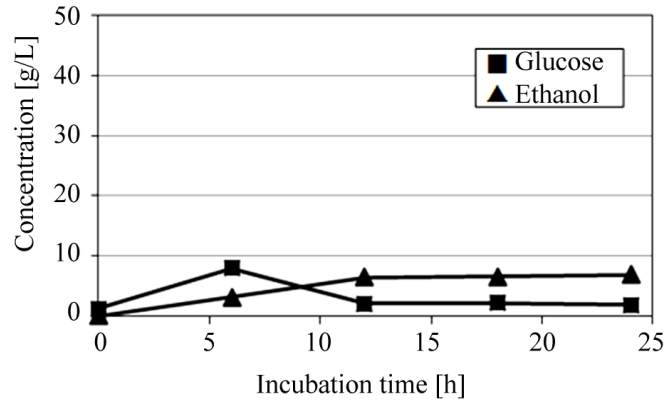

(a)

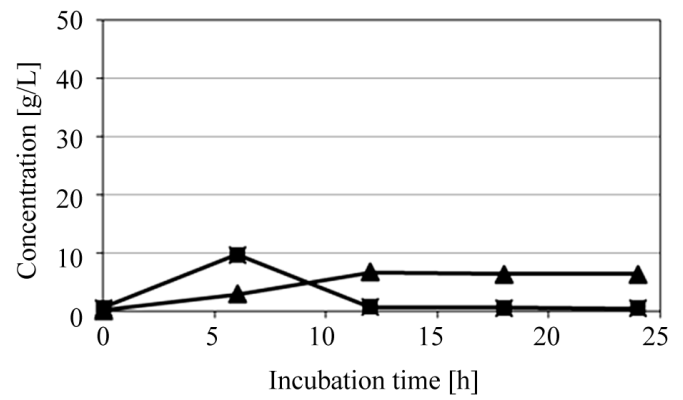

(b)

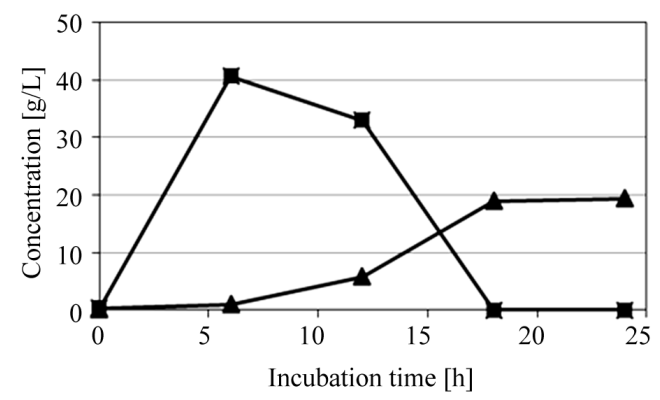

(c)

Figure 3. Time courses of glucose and ethanol in SSF of microalgae at pH 5 and $40^{\circ} \mathrm{C}$. (a) Microalgae crushed by a mortar; (b) Ultrasonic treated microalgae for $5 \mathrm{~min}$; and (c) Ultrasonic treated microalgae for $30 \mathrm{~min}$.

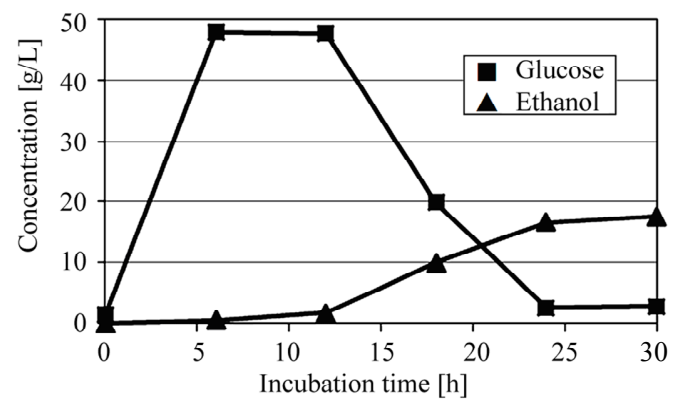

Figure 4. Time courses of glucose and ethanol in SSF of ultra-sonic treated microalgae for $\mathbf{3 0}$ min with no addition of nitrogen source at $\mathrm{pH} 5$ and $40^{\circ} \mathrm{C}$.

$\mathrm{g} / \mathrm{L}$ of ethanol was obtained at an incubation time of $30 \mathrm{~h}$, the ethanol production rate and the ethanol yield were a little lower than those of the result as shown in Figure 3(c). Furthermore, the glucose was not consumed completely and some glucose remained even after an incubation time of $30 \mathrm{~min}$. This reason seems to be attributed to lack of nitrogen source. However, since the ethanol yield was a comparatively high value, i.e. $0.168 \mathrm{~g} / \mathrm{g}$-dry microalgae, which corresponds to $68.8 \%$ of the theoretical yield, it was found that the ultrasonic treated microalgae was used as not only carbon but also nitrogen sources.

\section{Conclusion}

The present work aims at clarifying the effect of ultrasonic treatment using a homogenizer on the extraction of starch from microalgae and converting the extracted starch into ethanol efficiently by the simultaneous saccharification and fermentation. The ultrasonic treatment could extract the starch contained in the microalgae almost completely. The ethanol production from the extracted starch solution obtained from the ultrasonic treated microalgae was attempted using SSF and the comparatively high ethanol yields, i.e. about $70 \%-80 \%$ of the theoretical value, with and without the addition of nitrogen source, i.e. yeast extract. Since the ultrasonic treatment uses no chemical reagents such as acids and organic solvents, it seems to be an environmentally friendly method. Therefore, it was confirmed that the ultrasonic treatment is an effective pretreatment method of microalgae not only for ethanol production but also for environmental protection. Furthermore, since this method was effective for the cell wall degradation of microalgae, this might be applied on an industrial scale to the effecttive extraction of not only starch but also lipid contained in microalgae. Future study will be focused on the comparisons with other technologies in terms of efficiency, costs, and etc.

\section{REFERENCES}

[1] A. E. Farrell, R. J. Plevin, B. T. Turner, A. D. Jones, M. O'Hare and D. M. Kammen, "Ethanol Can Contribute to Energy and Environmental Goal," Science, Vol. 311, No. 5760, 2006, pp. 506-508. doi:10.1126/science.1121416

[2] H. Blottniz and M. A. Curran, "A Review of Assessments Conducted on Bio-Ethanol as a Transportation Fuel from a Net Energy, Greenhouse Gas, and Environmental Life Cycle Perspective," Journal of Cleaner Production, Vol. 15 , No. 7, 2007, pp. 607-619. doi:10.1016/i.jclepro.2006.03.002

[3] P. Adapa, L. Tabil and G. Schoenau, "Grinding Performance and Physical Properties of Non-Treated and Steam Exploded Barley, Canola, Oat and Wheat Straw," Biomass Bioeregy, Vol. 35, No. 1, 2011, pp. 549-561.

[4] X. Pan, D. Xie, K. Y. Kang, S. L. Yoon, J. N. Saddler, "Effect of Organosolv Ethanol Pretreatment Variables on Physical Characteristics of Hybrid Poplar Substrates," Ap- 
plied Biochemistry and Biotechnology, Vol. 137-140, No. 1-12, 2007, pp. 367-377. doi:10.1007/s12010-007-9065-Z

[5] C. Asada, C. Sasaki, Y. Uto, J. Sakafuji, Y. Nakamura "Effect of Steam Explosion Pretreatment with Ultra-High Temperature and Pressure on Effective Utilization of Softwood Biomass," Biochemical Engineering Journal, Vol. 60, No. 2012, pp. 25-29. doi:10.1016/j.bej.2011.09.013

[6] M. Matsumoto, H. Yokouchi, N. Suzuki, H. Ohata and T. Matsunaga, "Saccharification of Marine Microalgae Using Marine Bacteria for Ethanol Production," Applied Biochemistry and Biotechnology, Vol. 105, No. 1-3, 2003, pp. 247-254. doi:10.1385/ABAB:105:1-3:247

[7] S. P. Choi, M. T. Nguyen and S. J. Sim, "Enzymatic Pretreatment of Chlamydomonas reinhardtii Biomass for Ethanol Production," Bioresource Technology, Vol. 101, No. 14, 2010, pp. 5330-5336. doi:10.1016/j.biortech.2010.02.026

[8] R. P. John, G. S. Anisha, K. M. Nampoothiri and A. Pandey, "Micro and Microalgal Biomass: A Renewable Source for Bioethanol," Bioresource Technology, Vol. 102, No. 1, 2011, pp. 186-193. doi:10.1016/j.biortech.2010.06.139

[9] E. Suali and R. Sarbatly, "Conversion of Microalgae to Biofuel," Renewable and Sustainable Energy Reviews, Vol. 16, No. 6, 2012, pp. 4316-4342. doi:10.1016/j.rser.2012.03.047

[10] J. Qian, X. Chen, X. Ying and B. Lv, "Optimisation of Porous Starch Preparation by Ultrasonic Pretreatment Followed by Enzymatic Hydrolysis," International Journal of Food Science \& Technology, Vol. 46, No. 1, 2011, pp. 179-185. doi:10.1111/j.1365-2621.2010.02469.x
[11] Q. Huang, L. Li, X. Fu, "Ultrasound Effects on the Structure and Chemical Reactivity of Cornstarch Granules," Starch, Vol. 59, No. 8, 2007, pp. 371-378. doi:10.1002/star.200700614

[12] F. F. Lima, C. T. Andrade, "Effect of Melt-Processing and Ultrasonic Treatment on Physical Properties of High Amylase Maize Starch," Ultrasonics Sonochemistry, Vol. 17, No. 4, 2010, pp. 637-641. doi:10.1016/j.ultsonch.2010.01.001

[13] M. M. Lomboy, S. K. Khanal, J. Leeuwen, D. R. Raman and D. Grewell, "Simultaneous Saccharification and Fermentation and Economic Evaluation of Ultrasonic and Jet Cooking Pretreatment of Corn Slurry," Biotechnology Progress, Vol. 27, No. 6, 2011, pp. 1561-1569. doi:10.1002/btpr.677

[14] L. H. Grimme, N. K. Boardman, "Photochemical Activities of a Particle Fraction $\mathrm{P}_{1}$ Obtained from the Green Alga Chlorella fusca," Biochemical and Biophysical Research Communications, Vol. 49, No. 6, 1972, pp. 1617 1623. doi:10.1016/0006-291X(72)90527-X

[15] AOAC, "Official Method of Analysis," 13th Edition, In: W. Horwitz, Ed., Association of Official Analytical Chemist, Washington DC, 1980, pp. 56-132.

[16] H. Itoh, M. Wada, Y. Honda, M. Kuwahara and T. Watanabe, "Bioorganosolve Pretreatments for Simultaneous Saccharification and Fermentation of Beech Wood by Ethanolysis and White Rot Fungi," Journal of Biotechnology, Vol. 103, No. 3, 2003, pp. 273-280.

doi:10.1016/S0168-1656(03)00123-8 